\title{
PROBLEMATIZANDO A FAMÍLIA SOB NOVAS LÓGICAS DE CONSTITUIÇÃO E INTERAÇÃO
}

\section{La problematique de la famille face aux nouvelles logiques d'interaction et constitution}

\author{
Alexandra Resende Campos ${ }^{1}$
}

Resumo: O objetivo deste artigo é refletir sobre a concepção de família na contemporaneidade, levando em consideração as novas dinâmicas conjugais que ultrapassam o modelo de família nuclear concebida como uma instituição moderna. Pretende-se pensar também na complexidade que a noção de família pode apresentar nas pesquisas desenvolvidas no campo da Sociologia e outras áreas das Ciências Humanas, pois se trata de um grupo social heterogêneo e em constante processo de transformação. Para tanto, este artigo foi divido em três partes. A primeira discutirá as diferentes concepções de família e como este grupo é, na verdade, uma construção social. A segunda apresentará a família como uma importante agência socializadora no processo de constituição dos indivíduos. E a última parte abordará as novas configurações e dinâmicas familiares, enfatizando como a família se tornou um grupo aberto, dinâmico e instável.

Palavras-chave: Família. Sociologia. Mudanças Sociais.

Resume: Lobjectif de cet article est de discuter sur la notion de la famille dans le contemporain, considérant les nouvelles dynamiques conjugales qui vont au-delà du modèle de la famille nucléaire conçue comme une institution moderne. Il y a l'intention de penser aussi sur la complexité que la notion de famille peut avoir dans sur les recherches dans le domaine de la sociologie et d'autres dans les sciences humaines, parce que c'est un groupe sociale hétérogène et constamment en transformation. Donc, cet article est 
divisé en trois parties. La première discutera les différentes conceptions de la famille et comment ce groupe est, en effet, une construction sociale. La deuxième, présentera la famille comme une agence de socialisation important dans le processus de la constitution des individus. La dernière partie abordera les nouvelles configurations et dynamiques familiales, en mettant un accent sur comment la famille est devenue un groupe dynamique et instable.

Mots-Clé: Famille. Sociologie. Changements Sociaux. 


\section{Introdução}

Nos últimos anos, estudos e pesquisas desenvolvidas no campo das Ciências Humanas, como Antropologia, Sociologia e Educação, vêm demonstrando as variações das dinâmicas e dos estilos de vida existentes nas famílias, principalmente se considerarmos o fator classe social (DUARTE; GOMES, 2008; LAHIRE, 2008; BOURDIEU, 2007; LAREAU, 2007; FONSECA, 2005; SARTI, 2004, entre outros). Acredito ser essa diversidade existente nas configurações e dinâmicas familiares um desafio a ser enfrentado por pesquisadores e profissionais que se debruçam sobre esta temática (antropólogos, educadores, historiadores, sociólogos, psicólogos etc.), pois a família do século XXI é um grupo complexo, heterogêneo e aberto às transformações da sociedade.

A partir de uma abordagem sociológica, o objetivo deste artigo é refletir sobre a concepção de família na contemporaneidade, levando em consideração os novos ordenamentos e dinâmicas conjugais que ultrapassam o modelo de família nuclear concebida como uma instituição moderna. Pretende-se neste estudo pensar a família como um grupo social em constante processo de transformação e mudança. Um grupo flexível e dinâmico que ultrapassa a visão funcionalista de Parsons e Bales (1954), os preceitos morais e cristãos que valorizam o casamento religioso, a fidelidade e a estabilidade das uniões conjugais, entre outras vertentes que, muitas vezes, concebem a família em uma perspectiva normativa e tradicional.

O desafio deste artigo é pensar na complexidade que a noção de família apresenta na contemporaneidade. Essa complexidade em denominar ou conceituar o que vem a ser uma família se relaciona com as uniões conjugais cada vez mais heterogêneas e instáveis, com o aumento das uniões informais, o adiamento dos 
casamentos entre os jovens, as uniões homossexuais com ou sem adoção de filhos, o aumento do número de divórcios, a alteração dos papéis femininos e masculinos nas tarefas domésticas. Diante deste cenário tão diversificado é possível afirmar que a família nuclear moderna se encontra em um processo de "desinstitucionalização", como aponta Aboim (2006).

Para tanto, este artigo se divide em três momentos. No primeiro procuro discutir as diferentes concepções de família e como este grupo foi se constituindo como um produto das relações sociais. No segundo momento busco tratar da importância da família no processo de socialização dos diferentes sujeitos sociais, ou seja, a família como uma agência socializadora. E, por último, abordo as principais mudanças nas famílias contemporâneas, analisando as novas dinâmicas e configurações relativas a este grupo social. Ainda que tenha utilizado outros referenciais teóricos, os trabalhos de Almeida (2009), Aboim (2006), Bourdieu (1996) e Sarti $(2004,1996)$ foram fundamentais para a elaboração deste artigo.

\section{A família como produto de uma construção social}

A noção de família pode ser pensada como uma noção comum ou como um fato universal, uma vez que ela está incorporada no processo de constituição dos vários sujeitos sociais. Para Bourdieu (1996), a família pode ser pensada como uma pré-noção do senso comum, pois um princípio que foi inculcado por meio de um trabalho concreto de socialização dos vários agentes sociais. Assim, não é raro fazer uma associação ao se pensar em família como um grupo ordenado, unido por laços consanguíneos, composto por vários membros (pai, mãe e filhos) em que cada um desempenha o seu papel dentro do grupo. Aliás, segundo a definição de Ferreira (1986, p. 755), 
em o Novo dicionário Aurélio, a concepção de família não vai além desses princípios incorporados no senso comum. Em seus vários significados a família aparece como "pessoas aparentadas que vivem, em geral, na mesma casa, particularmente o pai, a mãe e os filhos". "Pessoas do mesmo sangue". "Ascendência, linhagem, estirpe”. Ou ainda em uma visão sociológica, como define esta obra, encontra-se: "Comunidade constituída por um homem e uma mulher, unidos por laço matrimonial, e pelos filhos nascidos dessa união."

Ora, essa concepção de família foi marcante e bastante difundida paralela aos ideais de uma sociedade moderna cujo um dos objetivos era normatizar e disciplinar a civilização ocidental. Neste sentido, a escola e a família passaram a ser as principais instituições socializadoras responsáveis pela formação e disciplinarização das crianças. Vale ressaltar que a concepção de infância na Modernidade ${ }^{2}$ apresenta contribuições diretas para a valorização da família como uma instituição, assim como a escola moderna, que cumpre o papel de cuidar, proteger, educar ou, como bem define Foucault (1991), disciplinar.

Mesmo que a escola, a partir do século XVIII, tenha se tornado a principal instituição responsável pela formação das crianças, a família, que até então detinha o controle total sobre o processo de socialização de seus filhos, não desaparece no discurso pedagógico moderno. Por ser a criança considerada um ser imaturo e incompleto, ela precisava não só de um ambiente seguro e afetuoso, mas também de um adulto constante ao seu redor. Portanto, quando não estavam sob os olhos dos mestres, deveriam estar sob a tutela de um casal, ou seja, da família.

Segundo Bruschini (1989), a perspectiva histórica (Young e Willmott, 1973; Ariès, 1977; Poster, 1979, entre outros) aponta que, a partir do século XVIII, a família nuclear (composta por pai, mãe e filhos) consolidou-se como um modelo ideal para cuidar e proteger as crianças. 
Novas formas de intimidade entre pais e filhos, a supervalorização do amor materno, a privatização da instituição familiar e a passagem das funções socializadoras para o âmbito mais restrito do lar, constituem alguns dos mecanismos fundamentais para a constituição da família 'moderna', coincidindo com a ascensão da burguesia. (BRUSCHINI, 1989, p. 5).

Essa nuclearização da família moderna também se encontra no modelo de família funcionalista, sobretudo na obra de Parsons e Bales (1954), difundida no Brasil na segunda metade do século XX. Na perspectiva parsoniana, o modelo nuclear permitia um melhor ordenamento das funções desempenhadas pelos diferentes membros da família, tendo uma forte diferenciação no se refere a relação de gênero. Nesta configuração, a figura materna desempenha um papel fundamental no processo de socialização e desenvolvimento das crianças. A mãe é vista como a principal responsável pela criação e pelo cuidado dos filhos. Ao passo que a figura paterna caberia funções de caráter instrumental, como exercer atividades remuneradas fora do ambiente domiciliar. De acordo com Bruschini (1989, p. 2): "Há, no funcionalismo, uma ênfase acentuada na importância de que a criança tenha, nos primeiros estágios de desenvolvimento, uma relação especial, íntima e intensa com a mãe."

Com base neste modelo de família que se pretendia construir, é possível compreender a linearidade e coesão da família nuclear apresentada por Fortes (1958). Este antropólogo define três fases do que considerava como ponto universal do modelo de família nuclear. A primeira fase se refere a formação inicial (casamento), a segunda se relaciona com o nascimento dos filhos, seria a fase de expansão, e a terceira é o momento em que os filhos já adultos abandonam a casa dos pais para formar uma nova família, cujo autor denomina de fase do declínio (FONSECA, 2005). 
Vale destacar também a influência da moral cristã no que se refere à valorização pelo modelo de família nuclear, cuja porta de entrada é feita via casamento religioso. Neste modelo de família, concebido principalmente pela Igreja Católica, os ideais de fraternidade, solidariedade, harmonia, cumplicidade e, principalmente, de fidelidade estão presentes. Com base nestes preceitos, as dinâmicas familiares, enraizadas em uma concepção tradicional e normativa, não se distanciam do modelo de família moderna e funcionalista, em que a divisão de papéis entre homens e mulheres não deixam de ser delimitadas. $\mathrm{O}$ juramento matrimonial realizado, ainda hoje, entre maridos e esposas, perante um sacerdote da igreja, exemplifica claramente o modelo de família que se pretendia construir: "[...] prometo ser-te fiel, amar-te e respeitar-te, na alegria e na tristeza, na saúde e na doença, todos os dias na nossa vida.”’

Para Bourdieu (1996, p. 129), a família é um produto de um trabalho de instituição que é ao mesmo tempo ritual (casamento religioso) e técnico. Esse trabalho de instituição tem por objetivo garantir de forma duradoura alguns sentimentos que devem garantir a integração do grupo familiar. Na perspectiva bourdieusiana, a integração funciona como uma condição necessária para a persistência da unidade familiar. Além disso, "[...] os ritos de instituição (palavra que vem de stare, manterse, ser estável) visam constituir a família como uma entidade unida, integrada, unitária, logo, estável, constante, indiferente às flutuações dos sentimentos individuais."

Bourdieu (1996, p. 129), que denomina a família como "uma ficção bem fundamentada", aponta que para compreender esta instituição é necessário considerar o trabalho teórico e prático que transforma a obrigação de amar em disposição amorosa e, assim, permitir a criação do que ele denomina de "espírito de família". Esse "espírito de família" pode ser compreendido por uma série de atitudes presentes nas dinâmicas familiares, como 
generosidade, solidariedade, ajuda mútua entre seus membros, troca de gentilezas, entre outras.

Interessante também observar outras perspectivas de análise à luz do que chamamos de família. De acordo com Bruschini (1989), em estudo sobre o alcance e as limitações do conceito de família, é possível se deparar com várias concepções no que se refere às funções da instituição familiar. Ora ela é vista como um grupo responsável pela produção da força de trabalho, como agência socializadora responsável pela aprendizagem do respeito e da submissão, ora é vista como agência de reprodução ideológica.

$\mathrm{Na}$ primeira metade da década de 1970, o movimento feminista europeu e norte-americano tratou a família como um problema teórico do pensamento marxista, ressaltando o papel do trabalho doméstico para a reprodução da força de trabalho.

Segundo essa vertente do marxismo a família seria um grupo social voltado para a reprodução da força de trabalho, no qual os membros do sexo feminino se encarregariam da produção de valores de uso na esfera privada, cabendo aos homens a produção de valores de troca, através da venda de sua força de trabalho no mercado. (BRUSCHINI, 1989, p. 3).

Assim, a família pode ser pensada como uma unidade de sobrevivência econômica. A família deveria funcionar, sobretudo nos pressupostos da família moderna, como um grupo que produz recursos materiais necessários para a estabilidade das dinâmicas familiares. Em outras palavras, um grupo que se constitui pela troca recíproca de bens materiais e econômicos. Neste sentido, Kellerhals et al. (1982, 2000 apud ABOIM, 2006) ressalta que a família possui funções instrumentais relativas a produção econômica, de educação e de apoio material. 
Já a Escola de Frankfurt concebe a família como um local de adestramento e adequação para a vida social, um local em que se aprende a ser submisso e a respeitar a autoridade. Assim, essa vertente de pensamento faz uma crítica à autoridade estabelecida entre pai e filho, uma vez que os filhos desde pequenos devem respeitar a figura paterna.

Bruschini (1989) aponta a visão de família realizada por Heller (1971, 1972, 1982), em que a família aparece como reprodução ideológica. Para esta autora, a vida cotidiana se revela como um dos meios fundamentais para a reprodução de ideias, atos e relações.

Apesar da concepção de família ser diversa e complexa, ela aparece fortemente como uma instituição social que foi construída historicamente, principalmente se considerarmos o processo de civilização no Ocidente no século XVIII ${ }^{4}$. Portanto, tomo as palavras de Bourdieu (1996) para afirmar que a família que conhecemos, que muitas vezes se apresenta com a aparência de algo natural, é, na verdade, uma invenção social recente. Assim este pensador aponta que a família é na verdade uma ficção, um artefato social, uma ilusão bem fundamentada ou mesmo apenas uma palavra. Nesta mesma perspectiva, Sarti $(2004$, p. 13) aponta que a família deve ser algo que se define como:

[...] uma história que se conta aos indivíduos desde que nascem, ao longo do tempo, por palavras, gestos, atitudes ou silêncios e que será, por eles, reproduzida e re-significada, à sua maneira, dados os distintos lugares e momentos dos indivíduos na família. Vista como uma realidade que se constitui pela linguagem, socialmente elaborada e internalizada pelos indivíduos, a família torna-se um campo privilegiado para se pensar a relação entre o individual e o coletivo, portanto, entre mim e o outro. 


\section{A família como agência socializadora}

É inegável a influência da família no processo de socialização dos diferentes sujeitos sociais. Por se tratar de um princípio comum em diversas culturas e sociedades, a família pode ser tratada como um objeto de grande importância para os estudos e pesquisas desenvolvidas nas Ciências Humanas. Esta relevância se relaciona ao fato da família ser a responsável pelas primeiras percepções, valores e crenças sobre o mundo social.

Segundo Sarti (2004, p. 17), podemos pensar na família como um lugar em que se aprendem as primeiras falas, onde se constrói a imagem do mundo exterior e interior, local de ordenação e sentido das experiências vividas. Independente do contexto social, a família seria “[...] o filtro através do qual se começa a ver e a significar o mundo. Esse processo que se inicia ao nascer entende-se ao longo de toda vida, a partir dos diferentes lugares que se ocupa na família." É neste sentido que podemos pensar na família como instância de socialização responsável pela incorporação do habitus primário ${ }^{5}$ (BOURDIEU, 1996).

Entendendo o habitus como algo incorporado ao longo da nossa trajetória de vida, por meio da nossa história e dos processos de interação social, compreende-se a importância da família nos estudos sociológicos, uma vez que é por intermédio dos processos de interação familiar que ocorrem os primeiros processos de socialização. Sendo assim, a família é tratada, no âmbito da Sociologia, como uma agência de socialização primária.

Mesmo que os diferentes sujeitos, ao longo de suas trajetórias de vida, compartilhem outros modos de socialização que ultrapassam a esfera familiar (escola, grupo de pares, amizades, namoros, grupos religiosos, entre outros), e assim, progressivamente, vão constituindo e reestruturando o habitus 
primário, é na socialização primária ou, dito de outra forma, na socialização familiar que ocorre a incorporação das disposições ${ }^{6}$ mais duradouras dos indivíduos, os esquemas de percepção, classificação e ação. Dessa forma, os processos de incorporação e constituição do habitus primário não podem ser pensados sem considerar as diferentes posições sociais ocupadas pelos indivíduos, bem como suas trajetórias. Logo, podemos pensar em variantes estruturais do habitus ou também em variantes do modo de socialização familiar.

Portanto, ao se pensar nos modos de socialização familiar, é necessário considerar que existem variações de acordo com o contexto e grupo social em que as famílias estão inseridas. Assim também ocorre com a concepção de família, uma vez que esta apresenta diferenças de acordo com cada classe e variáveis sociais: capital escolar e econômico, envolvimento religioso, situação profissional, tipo de união conjugal, entre outros aspectos.

Em meios populares a família pode ser vista como uma referência, uma "ordem simbólica” (SARTI, 2004). Pesquisas realizadas tanto no campo da Antropologia quanto no da Sociologia revelam que a família nas camadas populares se caracteriza fortemente pelas relações que seus membros estabelecem com seus pares, no sentido de prestar apoio mútuo diante de situações conflituosas, como divórcio, dificuldades financeiras, desemprego, instabilidade mobiliária, auxílio nos cuidados dos filhos, perda de um ente querido, entre outros acontecimentos (DUARTE; GOMES, 2008, FONSECA, 2005, 1999; SARTI, 1996, 2004). São por meio dessas ligações, afetiva e material, que os indivíduos dão significados às relações sociais que extrapolam o círculo familiar, seja no mercado de trabalho, na instituição escolar, no grupo de amigos, seja nas relações com a vizinhança, entre outras. 
A família não é apenas o elo afetivo mais forte dos pobres, o núcleo da sua sobrevivência material e espiritual, o instrumento através do qual viabilizam seu modo de vida, mas é o próprio substrato de sua identidade social. Em poucas palavras, a família é uma questão ontológica para os pobres. (SARTI, 1996, p. 33).

Neste sentido, as famílias populares devem ser pensadas como uma rede e não como um núcleo composto apenas por pai, mãe e filhos, no sentido tradicional da família moderna. Assim, a família nos meios populares pode ser pensada como uma rede que ultrapassa os laços biológicos. De acordo com Fonseca (2005, p. 52), os laços familiares são marcados “[...] pela identificação estreita e duradoura entre determinadas pessoas que reconhecem entre elas certos direitos e obrigações mútuos." Portanto, essas relações não se restringem às redes de relações consanguíneas, dizem respeito também às redes de relações territoriais, amizades, compadrio, adoções e na ajuda de atividades comuns.

Enquanto nos meios populares a noção de família extrapola os limites dos parentes consanguíneos e da organização nuclear, Bourdieu (1996) destaca que uma das características das classes dominantes é a de possuírem famílias extensas e integradas. Estas são unidas por intermédio de uma relação de interesses, cujo objetivo é preservar a posse de capital econômico, social ${ }^{7}$ e simbólico (o nome da família). Como aponta Fonseca (2005), nas elites prevalece a ideia de linhagem, de patrimônio a ser herdado. Já em relação às classes médias podemos caracterizálas pelo espírito individualista, em que todos os recursos são investidos na educação e formação profissional dos filhos, além do desejo de ascensão social em direção às elites (RAPP, 1992; NOGUEIRA; NOGUEIRA, 2002).

Contudo, é possível perceber a complexidade existente em se tratar da noção de família em estudos e pesquisas desenvolvidas 
no campo das Ciências Humanas. Mesmo que podemos encontrar alguns pontos em comuns relativos não só a família como uma instituição social, mas também como uma agência socializadora, é de fundamental importância considerar a heterogeneidade deste termo ao realizar pesquisas cujo foco de interesse seja este grupo. O contexto cultural, social e econômico pode revelar características bastante divergentes ao ideal de família preconizado a partir do século XVIII com a sociedade moderna. Além disso, se considerarmos a família existente na contemporaneidade, é possível observar que não encontramos mais um "modelo" de família. Diante das atuais configurações e dinâmicas familiares (uniões instáveis, divórcios, uniões homossexuais, ausência de filhos nos casamentos, adiamento do casamento entre os jovens, entre outros aspectos), o termo "novas conjugalidades", utilizado por Aboim (2006), a meu ver, caracteriza melhor as famílias na contemporaneidade.

\section{A diluição do modelo familiar: que grupo social é este?}

Cada vez mais fica evidente que a família nuclear se torna uma armadilha, um ralo cultural, uma secreta implosão neurótica de átomos rompidos. (BEY, 2011, p. 11).

Nesta parte do texto pretendo tomar como foco os novos modelos e dinâmicas familiares existentes em nossa sociedade, considerando os diversos modos de uniões conjugais e as novas relações entre casais e entre pais e filhos. As famílias ${ }^{8}$ na atualidade apresentam uma série de características diversas ao modelo de família que se convencionou com os ideais morais, cristãos e modernos. Verifica-se um processo de desfragmentação, instabilidade, individualização e não formalização nos modos de vida relativos às famílias. Seria o 
processo de desinstitucionalização das uniões conjugais ou de desfamilialização (ESPING-ANDERSON, 1999 apud ABOIM, 2006).

Bruschini (1989, p. 5) já apontava a ineficácia do modelo de família nuclear e conjugal predominante em nossa sociedade, principalmente quando aplicada à realidade empírica. Para esta autora, a mutabilidade e elasticidade seria uma das principais características da instituição familiar, pois “[...] a existência de um modelo numa sociedade ou momento histórico determinado não significa que este conjunto de regras e padrões de comportamento não seja passível de transformações.” Aboim (2006) também aponta para essa flexibilidade do modelo familiar quando afirma que família e mudança são termos inevitavelmente acoplados.

De acordo com o Comunicado número 64 do Instituto de Pesquisa Econômica Aplicada (IPEA), PNAD 2009 - Primeiras Análises: Tendências Demográficas, a família brasileira vem sofrendo algumas alterações relativas aos arranjos familiares (crescimento do número de lares chefiados por mulheres, aumento do número de casais sem filhos, aumento do número de homens que moram sozinhos com filhos, entre outras configurações). Este mesmo estudo cita três revoluções sociais apontadas por Lesthaeghe (1995 apud IPEA, 2010) e que interferem diretamente nos arranjos familiares: a revolução contraceptiva; a revolução sexual, dissociando sexualidade e casamento; e a revolução no papel desempenhado por homens e mulheres nas dinâmicas familiares em que a mulher vem ocupando progressivamente a função de provedora. Como veremos, essas três revoluções realmente interferem no processo de formação das diferentes famílias, mas não se resumem somente a estes aspectos, outras variações também vem ocorrendo nas dinâmicas familiares como o aumento da afetividade entre os casais e entre pais e filhos, aumento do individualismo, a pouca durabilidade dos relacionamentos, entre outros fatores. 
Embora o modelo de família nuclear ainda seja predominante, o número de casais que não possuem filhos vem diminuindo progressivamente no Brasil. De acordo com dados do IPEA (Comunicado n. 64) no ano de 1992 o número de casais com a presença de filhos equivalia a 62,8\%, já em 2009 este índice cai para $49,9 \%$. Houve um aumento também no número de homens e mulheres que moram sozinhos, sem a presença de filhos. Vale ressaltar também que essas alterações nas famílias foram apontadas por Aboim (2006), em pesquisa referente às "novas conjugalidades" existentes em Portugal. Esta autora destaca ainda o aumento de filhos fora do casamento, o crescimento dos divórcios, o número de casais que optam pelas coabitações, entre outros modos de se viver a vida conjugal que ultrapassam a visão comum de família "ideal".

O casamento religioso, ou mesmo judicial, vem deixando de ser uma porta de entrada para o estabelecimento das uniões conjugais. Para Aboim (2006), as coabitações, ou seja, as uniões informais refletem o enfraquecimento da instituição matrimonial, deixando de ser a única forma legítima de se viver a conjugalidade. Além disso, este tipo de união revela formas de viver a conjugalidade voltadas para o bem-estar emocional, a realização individual e a igualdade entre o casal.

A opção pela coabitação aparece, muitas vezes, como uma opção de viver a conjugalidade de maneira descompromissada, uma relação cercada por condições incertas quanto à sua durabilidade. Por outro lado, a recusa pela união matrimonial formalizada também se relaciona com a diminuição dos fatores de regulação social externo. Assim, os indivíduos aceitam com maior facilidade alguns aspectos da vida conjugal que em outras épocas históricas seriam julgadas como "anormais" ou mesmo como "atos pecaminosos" (divórcio, instabilidade nos relacionamentos, gravidez em relacionamentos informais, uniões homossexuais etc.). 
De uma forma geral, as mudanças no casamentoinstituição foram agilizadas por um decréscimo da regulação social explícita dos comportamentos privados, que parecem ser realmente sentidos pelos indivíduos como cada vez mais privados, afrouxando as amarras subjectivas com o controlo da comunidade, do parentesco, da vizinhança. [...] sem dúvida, a estigmatização que no passado pesava sobre quem tinha percursos fora dos cânones do estreito dever-ser institucional sofreu mudanças profundas, enfraquecendo e perdendo poder condicionador. (ABOIM, 2006, p. 370).

Enfim, como ressalta Aboim (2006), são vários os motivos que levam os casais a optarem pela coabitação, possibilitando uma pluralização de modos informais de entrada na conjugalidade. Alguns preferem esta união pelo fato de terem vivenciado em uma primeira experiência conjugal este tipo de formalização, outros como recusa ideológica ou como uma maneira de experimentação antes de optarem pela formalização da união.

Importante apontar, neste aspecto, o valor ainda existente dos princípios morais cristãos no que se refere ao casamento religioso como condição sine qua non ao estabelecimento de uma vida conjugal. Aboim (2006) verificou que em Portugal as famílias que optam pelas uniões formais se concentram entre aquelas que possuem algum vínculo religioso e que possuem nível de escolaridade mais baixo. Esta socióloga também aponta para o processo de laicização do casamento, uma vez que vem ocorrendo um aumento progressivo das uniões formais via casamento civil em detrimento das uniões via casamento religioso.

Outra mudança verificada nas famílias diz respeito às relações estabelecidas entre seus membros. A afetividade aparece com um componente forte nestas "novas conjugalidades", ou seja, podemos apontar para a passagem de uma concepção de família 
instrumental e normativa para uma família como uma unidade de afeto. Neste sentido podemos analisar a relação estabelecida entre a figura paterna e os filhos, em que os pais vão deixando de ser vistos como "chefe" da família, sinônimo de autoridade e respeito para os filhos, como já criticava a Escola de Frankfurt.

Almeida (2009), em sua tese de doutorado sobre os processos de individuação e o valor da autonomia entre jovens adolescentes e suas famílias, aponta para este afrouxamento de poder e autoridade exercida pela figura paterna. Esta autora ressalta a atualidade do pensamento de Toqueville, ainda no século XIX, sobre a relação entre pais e filhos. Em uma perspectiva menos tradicional, Toqueville menciona a figura paterna como alguém que estabelece relações afetivas e de confiança com os filhos.

Eu penso que à medida que os modos e as leis se tornam mais democráticas, as relações entre pai e filho tornamse mais íntimas e afectivas; as regras e a autoridade são menos faladas; a confidência e a ternura aumentam com freqüência, e o laço natural será fortalecido à medida que o laço social enfraquece. Numa família democrática o pai exerce nenhum outro poder que não o que é atribuído pelo afecto e pela experiência de idade; as suas ordens serão porventura desobedecidas, mas o seu conselho é na maioria das vezes convincente. (TOQUEVILLE, 1863 [1835-1840], p. 237 apud ALMEIDA, 2009, p. 102).

De fato, as relações estabelecidas entre pais e filhos revelam uma maior proximidade no que se refere à troca de carinhos nas novas dinâmicas familiares. $\mathrm{O}$ pai deixa de ser visto como um "[...] depositário da autoridade e disciplina familiar." (ALMEIDA, 2009 , p. 209). Em outras palavras, as atitudes paternas deixam de ser concebidas como meramente normativas. As relações de proximidade, estabelecidas entre pais e filhos, são apontadas por Almeida (2009) como um dos pontos mais tratados pelas 
pesquisas que focalizam as transformações ocorridas nas dinâmicas familiares com o avançar da modernidade.

Paralelo a essas relações de proximidade afetiva, Almeida (2009) também ressalta o enfraquecimento da obediência e do respeito às regras por parte dos filhos seria um processo de afrouxamento da autoridade materna e paterna. Contudo, não podemos deixar de considerar que essa "desobediência", apontada pela autora, não está desvinculada de outras transformações, como o lugar da infância em nossa sociedade. Concebida como um ser imaturo e que requer cuidados especiais, a infância, como uma construção moderna, propiciou a produção de uma série de conhecimentos acerca desta categoria social (psicologia infantil, pediatria, entre outros), além da interferência estatal que utiliza de mecanismos para legitimar a especificidade deste grupo. Assim, essa difusão de conhecimento produzido permitiu um novo olhar sobre a infância, logo, trazendo influências diretas no modo de lidar com esta população.

Dessa forma, a "desobediência" dos filhos revela as mudanças ocorridas nas relações entre adultos e crianças. Na família tradicional o respeito aos pais poderiam ser confundidos com o medo pelos castigos corporais, situação que vem sendo cada vez mais abolida, haja vista a influência do Estatuto da Criança e do Adolescente (ECA), aprovado no início da década de 1990.

Por outro lado, essa maior proximidade afetiva entre pais e filhos não pode ser tomada como uma constante das novas relações familiares, pois existem variações referentes ao contexto sociocultural em que as famílias estão inseridas. Lareau (2007), em sua pesquisa sobre os estilos educativos de famílias negras e brancas, verifica que são as famílias de classe média que estabelecem relações mais abertas e fazem o uso constante do diálogo. Já Campos (2010), em pesquisa sobre as práticas de escolarização de famílias rurais, observou que são as famílias que possuem maior nível de escolaridade que estabelecem relações 
mais afetuosas e utilizam do diálogo para resolver conflitos e desentendimentos entre seus membros.

Se, por um lado, o sentimento de afeto, a livre escolha de parceiros, a crescente privatização da vida familiar são características marcantes nas dinâmicas familiares contemporâneas, a unidade familiar não deixou de ser também um lugar de apoio material, ajuda mútua e sobrevivência econômica. Acrescenta-se também nestas novas interações a desvinculação afetiva do grupo familiar para a construção de uma trajetória individual e realização pessoal. Se a família moderna se caracterizava como um ponto de referência constante e um lugar de segurança para seus membros, nas novas relações familiares existe um processo de liberação e desvinculação dos laços de parentesco. Nobert Elias aponta muito bem para esta questão, chamando este processo de desafiliação relativa:

Durante muito tempo, os homens pertenceram às suas famílias para a vida e para a morte. [...] A transformação decisiva que se processou na identidade do Nós, e nas cargas afectivas respectivas em relação à família, reside, em grande parte, no facto de já não ser impossível escapar à família enquanto grupo do Nós. O indivíduo, a partir de certa idade, pode retirar-se da família, normalmente sem perda de oportunidades de sobrevivência, físicas ou sociais. (ELIAS, 1993 [1987], p. 226-227 apud ALMEIDA, 2009, p. 94).

Outra mudança também verificada nas dinâmicas familiares se refere a relação de gênero estabelecida entre maridos e esposas. Mesmo que as mulheres ainda sejam as principais responsáveis pelos serviços domésticos e pelo cuidado dos filhos não se pode negar uma busca crescente pela igualdade de papéis nas constituições familiares. Esta mudança vem acompanhada da crescente independência financeira e profissional das mulheres 
e também por uma recusa aos papéis pré-fabricados referentes às funções femininas e masculinas no interior das "novas conjugalidades”. Neste caso, podemos observar essas alterações até mesmo em alguns contextos sociais em que as funções desempenhadas por homens e mulheres se apresentavam mais delimitadas, como as famílias rurais, em que as mulheres, em sua maioria, eram as principais responsáveis pelos serviços domésticos e pelo cuidado dos filhos. Campos (2010) verificou, em algumas dinâmicas familiares, um envolvimento significativo dos maridos com atividades ligadas ao ordenamento e limpeza das casas, como também a responsabilidade de tomar conta dos filhos enquanto suas esposas exercem atividades remuneradas no meio urbano.

Sobre essas alterações, Aboim (2006, p. 46) aponta que a crescente autonomia e igualdade das mulheres, a busca pela realização profissional, a recusa dos papéis pré-fabricados ou o questionamento das identidades tradicionais são, na verdade, reflexos das novas transformações em curso nas famílias. Para esta autora, estas tendências possibilitam “[...] novos ideários de afectividade, de relação, de igualdade de gênero, e também, por conseqüência, renovadas 'tensões' entre a construção da individualidade e a 'pertença feliz' ao duo conjugal e ao grupo familiar [...].'

O que se percebe nas novas dinâmicas e interações conjugais (relacionamentos mais instáveis e abertos, uniões sem a presença ou redução do número de filhos, busca pela igualdade de papéis entre homens e mulheres, aumento dos divórcios, nascimento de filhos em uniões instáveis, as coabitações, entre outros aspectos) é uma busca pela individualidade cada vez mais crescente em nossa sociedade.

Verifica-se um movimento constante no processo de constituição dos arranjos e dinâmicas familiares que estão diretamente relacionadas às transformações sociais. Roussel (1980, 1992 apud ABOIM, 2006, p. 216) propõe quatro 
modelos de família que têm como fundamento as mudanças que vem ocorrendo nas relações privadas da vida familiar. $\mathrm{O}$ primeiro modelo seria a "família-instituição", ou seja, famílias que se caracterizam pelas estratégias de sobrevivência e pela subordinação do matrimônio. O segundo modelo são as "famílias-aliança", ainda institucionalizadas, porém unidas pelo amor romântico. A terceira seria as "famílias-fusão", em que prevalece o amor romântico, mas existe uma recusa da instituição tradicional e uma busca pela igualdade entre os cônjuges. E o último modelo de família apontado por Roussel seria as "famílias-associação", caracterizadas pelo individualismo acima do elo conjugal.

Contudo, fica evidente como a família é uma instituição em permanente processo de mutação, uma instituição que não está isolada das transformações sociais e dos diferentes momentos históricos. Logo podemos observar a complexidade em conceituar este grupo social como uma instância única e homogênea, haja vista as variações existentes de acordo com os diferentes contextos histórico-culturais.

\section{Considerações finais}

No decorrer da história é inegável a importância da família no processo de constituição dos diferentes sujeitos sociais. Mesmo que em algumas épocas a instituição familiar seja caracterizada principalmente por um caráter instrumental, de ajuda mútua e sobrevivência econômica entre seus membros, ou mesmo na contemporaneidade por um grupo unido por laços afetivos e amorosos, a família não deixou de ser tratada, sobretudo, no campo das ciências sociais, como uma importante agência de 
socialização. Ainda que ela se encontre em um processo de "desinstitucionalização", como aponta Aboim (2006), a noção de família se encontra presente no discurso comum e está inserida em vários contextos socioculturais.

Ao considerar esse processo de "desinstitucionalização" da família, énecessário perceber que não se trata do desaparecimento deste grupo social, mas sim de uma nova configuração de laços conjugais que tendem a caminhar em sentidos opostos da noção de família tradicional e nuclear enraizada no senso comum. Trata-se na verdade de uma abertura das dinâmicas e das relações estabelecidas no interior deste grupo. As famílias em nossa sociedade perderam o status de uma instituição fechada, estável e ordenada para um grupo em constante processo de mudança, em que as realizações pessoais prevalecem sobre o interesse do grupo familiar como um todo.

Com o processo de privatização da vida familiar o que importa mais é o bem-estar dos indivíduos inseridos neste grupo. Logo, podemos pensar no crescimento dos divórcios e na recusa pelas uniões formais como uma nova forma de gerir as uniões conjugais para além dos controles externos de caráter normativo. Nas novas configurações familiares, a intimidade, o sentimento amoroso e sexual são aspectos fundamentais para a permanência da vida conjugal e familiar.

Contudo, alguns aspectos da vida familiar ainda aparecem como características principais: a vida conjugal a dois e a presença de filhos. Vale lembrar também o papel da mulher nas dinâmicas familiares. Mesmo que existe uma crescente busca pela igualdade de gênero nos relacionamentos, é a figura feminina, na maioria das constituições familiares, a principal responsável pelos serviços domésticos e pelo cuidado dos filhos, mesmo quando maridos e esposas exerçam atividades remuneradas fora do domicílio. Em outros casos, em que existe a paridade de papéis, geralmente o casal conta com o apoio de 
uma profissional, em sua maioria do sexo feminino, ou seja, a empregada doméstica.

Diante do exposto fica evidente o desafio sociológico que existe ao tomar as famílias como foco de estudos e pesquisas. Penso que o grande desafio das pesquisas desenvolvidas neste campo de conhecimento é compreender, à luz das mudanças e das diversidades conjugais, as novas interações e dinâmicas familiares existentes na contemporaneidade. Considerando, assim, a família como um grupo social, dinâmico e flexível, caminhando para além da concepção comum da família nuclear e moderna, principalmente se considerarmos a lacuna existente sobre pesquisas que tratam das dinâmicas familiares em uniões conjugais homossexuais, um tema pertinente e considerável de ser abordado, haja vista o crescimento significativo desse tipo de união.

\section{Referências}

ABOIM, S. Conjugalidades em Mudança. Lisboa: Imprensa de Ciências Sociais, 2006.

ALMEIDA, L. P. R. d' Juventude, Família e Autonomia: entre a norma social e os processos de individuação. 2009. 512 f. Tese (Doutorado) Universidade de Lisboa. Lisboa, 2009.

ARIÈS, P. História social da criança e da família. Rio de Janeiro: Zahar, 1981.

BEY, H. Zona Autônoma Temporária. Rio de Janeiro: Rizoma, 2011.

BOURDIEU, P. A escola conservadora: as desigualdades frente à escola e à cultura. In: NOGUEIRA, M. A.; CATANI, A. (Orgs.). Escritos de educação. Petrópolis: Vozes, 1998. p. 39-64. 
. Esboço de uma teoria a prática. In: ORTIZ, R. (Org.). Pierre Bourdieu: Sociologia. São Paulo: Ática, 1983.

O habitus e o espaço dos estilos de vida. In: A distinção: crítica social do julgamento. São Paulo: EDUSP; Porto Alegre: ZOUK, 2007. p. 62-211.

Razões Práticas: sobre a teoria da ação. Campinas: Papirus, 1996.

BRUSCHINI, C. Uma abordagem sociológica de família. Rev. Bras. Est. Pop., São Paulo, v. 6, n. 1, p. 1-23, jan./jun. 1989.

CAMPOS, A. R. As práticas de escolarização de famílias rurais: um estudo comparativo entre famílias negras, mestiças e brancas do povoado de Goiabeiras, São João del-Rei, MG. 2010, 187 f. Dissertação (Mestrado em Educação) - Universidade Federal Fluminense, Niterói, 2010.

DANDURAND, P.; OLLIVIER, É. Os paradigmas perdidos: ensaio sobre a Sociologia da Educação e seu objeto. Revista Teoria e Educação, Porto Alegre, n. 3, p. 120-142, 1991.

DUARTE, L. F. D.; GOMES, E. Três famílias: identidades e trajetórias transgeracionais nas classes populares. Rio de Janeiro: FGV, 2008.

FERREIRA, A. B. de H. Novo Dicionário da Língua Portuguesa. 2. ed. Rio de Janeiro: Nova Fronteira, 1986.

FONSECA, C. Concepções de família e práticas de intervenção: uma contribuição antropológica. Revista Saúde e Sociedade, São Paulo, v. 14, n. 2, p. 50-59, maio-ago. 2005.

. Quando cada caso NÃO é um caso: pesquisa etnográfica e educação. Revista Brasileira de Educação, n. 10, p. 58-78, jan./abr. 1999.

FORTES, M. Introduction. In: GOODY, J. (Org.). Development cycles in domestic groups. London: Cambridge University Press, 1958. p. 1-14. 
FOUCAULT, M. Vigiar e Punir: história das violências nas prisões. 9. ed. Petrópolis: Vozes, 1991.

INSTITUTO DE PESQUISA ECONÔMICA APLICADA. PNAD Primeiras Análises: Tendências Demográficas. Instituto de Pesquisa Econômica Aplicada (IPEA), 2010. Disponível em:

<http://www.ipea.gov.br/portal/images/stories/PDFs/ comunicado/101013_comunicadoipea64.pdf >. Acesso em: 15 jul. 2010.

LAHIRE, B. Sucesso escolar nos meios populares: as razões do improvável. São Paulo: Ática, 2008.

LAREAU, A. A desigualdade invisível: o papel da classe social na criação dos filhos em famílias negras e brancas. Educação em Revista, Belo Horizonte, n. 46, p. 13-82, dez. 2007.

NOGUEIRA, M. A.; NOGUEIRA, C. A Sociologia da educação de Pierre Bourdieu: limites e contribuições. Educação e Sociedade, n. 78, p. 15-36, 2002.

PARSONS, T.; BALES, R. F. Family socialization and interaction process. Glencoe, III: Free Press, 1954.

RAPP, R. Family and class in contemporary America: notes toward an understanding of ideology. In: THORN, B.; YALOM, M. (Org.). Rethinking the family: some feminist questions. Boston: Northeastern University Press, 1992. p. 49-70.

ROUSSEAU, J. J. Émile ou de léducation. Paris: Edimat Libros, 1967.

SARTI, C. A. A família como espelho: um estudo sobre a moral dos pobres. Campinas: Autores Associados, 1996.

A família como ordem simbólica. Psicologia USP, v. 15, n. 3, p. 11-28, 2004. 
SPOSITO, M. P. Uma perspectiva não escolar no estudo sociológico da escola. In: PAIXÃO, L. P.; ZAGO, N. (Orgs.). Sociologia da Educação: pesquisa e realidade brasileira. Petrópolis: Vozes, 2007. p. 19-43.

\section{Notas}

${ }^{1}$ Doutoranda em Educação pela Universidade Federal Fluminense (UFF), bolsista da Capes. Endereço para contato: Av. Luiz Giarola, n. 1957, Colônia do Marçal, São João del-Rei (MG), CEP: 36302-260. Endereço eletrônico: <xandinhacampos@yahoo.com.br>.

${ }^{2}$ A criança, como aponta Ariès (1981), deixa de ser concebida como um simples adulto em miniatura. Ela passa a ser vista como uma população que requer cuidados e atenção específicos, principalmente por parte dos adultos que se tornarão os grandes responsáveis pela formação desses novos seres. Assim como a família, a infância surge como uma categoria social, pois se trata de uma noção que é construída coletivamente, tanto pelo seu grupo de interesse (o discurso pedagógico moderno), quanto também pelo surgimento de novos especialistas que vão produzir saberes a respeito desta nova categoria (psicologia infantil, pediatria, entre outros).

${ }^{3}$ Trecho extraído do site <www.sdplviseu.web.pt/RITUAIS/matrimonio.html $>$. ${ }^{4}$ Momento este em que a escola e a família passam a ser as instituições responsáveis pelo processo de formação de uma nova categoria social que surgia, a infância, seres imaturos e incompletos, como apontou Rousseau (1967). ${ }^{5} \mathrm{O}$ conceito de habitus em Bourdieu pode ser pensado como "[...] sistema de disposições duráveis, estruturas estruturadas predispostas a funcionar como estruturas estruturantes, isto é, como princípio gerador e estruturador das práticas e das representações que podem ser objetivamente 'reguladas' e 'regulares' sem ser o produto da obediência a regras, objetivamente adaptadas a seu fim sem supor a intenção consciente dos fins e o domínio expresso das operações necessárias para atingi-los e coletivamente orquestradas, sem ser o produto da ação organizadora de um regente." (BOURDIEU, 1983, p. 61).

${ }^{6}$ Bourdieu (1983, p. 61) define por disposição "[...] em primeiro lugar, o resultado de uma ação organizadora, apresentando então um sentido próximo ao de palavras tais como estrutura; designa, por outro lado, uma maneira 
de ser, um estado habitual (em particular do corpo) e, em particular, uma predisposição, uma tendência, uma propensão ou uma inclinação."

${ }^{7}$ Segundo Bourdieu (1998), o capital social pode ser entendido como um conjunto de relações duradouras e úteis estabelecidas pelos indivíduos, no sentido de garantir ganhos materiais e simbólicos. Tais relações podem ser a curto ou longo prazo e se relacionam, por exemplo, com os tipos de interações que os sujeitos estabelecem com determinados indivíduos no trabalho, na vizinhança, na família, amigos, dentre outros.

8 Nesta parte do texto utilizarei a expressão famílias (no plural) no sentido de considerar a pluralidade dos modos de vida existentes em contraponto ao modelo de família nuclear e tradicional, ou seja, um grupo ordenado, coerente e estável. 